\title{
Review \\ High Selectivity Electrocatalysts for Oxygen Evolution Reaction and Anti-Chlorine Corrosion Strategies in Seawater Splitting
}

\author{
Shanshan Jiang ${ }^{1}$, Yang Liu ${ }^{1}$, Hao Qiu ${ }^{1}$, Chao Su ${ }^{1,2, *}$ and Zongping Shao ${ }^{2,3}$ \\ 1 School of Energy and Power, Jiangsu University of Science and Technology, Zhenjiang 212100, China; \\ jss522@just.edu.cn (S.J.); lynjit2022@163.com (Y.L.); haoqiu202202@163.com (H.Q.) \\ 2 WA School of Mines: Minerals, Energy and Chemical Engineering, Curtin University, \\ Perth, WA 6102, Australia; zongping.shao@curtin.edu.au \\ 3 State Key Laboratory of Materials-Oriented Chemical Engineering, College of Chemical Engineering, \\ Nanjing Tech University, Nanjing 211816, China \\ * Correspondence: chao.su@just.edu.cn
}

Citation: Jiang, S.; Liu, Y.; Qiu, H.; Su, C.; Shao, Z. High Selectivity Electrocatalysts for Oxygen Evolution Reaction and

Anti-Chlorine Corrosion Strategies in Seawater Splitting. Catalysts 2022, 12, 261. https://doi.org/10.3390/ catal12030261

Academic Editor: Yurii V. Geletii

Received: 27 January 2022

Accepted: 20 February 2022

Published: 25 February 2022

Publisher's Note: MDPI stays neutral with regard to jurisdictional claims in published maps and institutional affiliations.

Copyright: (C) 2022 by the authors. Licensee MDPI, Basel, Switzerland. This article is an open access article distributed under the terms and conditions of the Creative Commons Attribution (CC BY) license (https:// creativecommons.org/licenses/by/ $4.0 /$ )

\begin{abstract}
Seawater is one of the most abundant and clean hydrogen atom resources on our planet, so hydrogen production from seawater splitting has notable advantages. Direct electrolysis of seawater would not be in competition with growing demands for pure water. Using green electricity generated from renewable sources (e.g., solar, tidal, and wind energies), the direct electrolytic splitting of seawater into hydrogen and oxygen is a potentially attractive technology under the framework of carbon-neutral energy production. High selectivity and efficiency, as well as stable electrocatalysts, are prerequisites to facilitate the practical applications of seawater splitting. Even though the oxygen evolution reaction (OER) is thermodynamically favorable, the most desirable reaction process, the four-electron reaction, exhibits a high energy barrier. Furthermore, due to the presence of a high concentration of chloride ions $\left(\mathrm{Cl}^{-}\right)$in seawater, chlorine evolution reactions involving two electrons are more competitive. Therefore, intensive research efforts have been devoted to optimizing the design and construction of highly efficient and anticorrosive OER electrocatalysts. Based on this, in this review, we summarize the progress of recent research in advanced electrocatalysts for seawater splitting, with an emphasis on their remarkable OER selectivity and distinguished anti-chlorine corrosion performance, including the recent progress in seawater OER electrocatalysts with their corresponding optimized strategies. The future perspectives for the development of seawater-splitting electrocatalysts are also demonstrated.
\end{abstract}

Keywords: seawater electrolysis; oxygen evolution reaction; selectivity; anti-chlorine corrosion

\section{Introduction}

Current global energy supplies are mainly obtained from traditional fossil fuels such as coal, crude oil, and natural gas. The rising demand for energy and exhaustive exploitation of traditional sources are driving environmental pollution issues and energy dilemmas. To address these problems, many "green" technologies have been investigated to deploy renewable and environmentally friendly energy, such as solar, tidal, and wind energies [1-4]. Hydrogen is considered to be an ideal clean energy source for the future, and it can be produced by many methods, such as fossil fuel extraction, methane reorganization, photocatalytic water decomposition, and so on [5]. Among these, electrolytic water splitting provides an effective way to generate "green" hydrogen in addition to the above-mentioned intermittent renewable energy sources [6-9]. The obtained hydrogen can supply a clean and sustainable energy source as an alternative to fossil fuels, which avoids the $\mathrm{CO}_{2}$ emissions from traditional fuel combustion, and can be broadly used for transportation, heating, and energy-related fields. Water, especially fresh water, is indispensable to human life. Nowadays, industrial contamination, climate change, and population growth are all resulting in a shortage of clean water supplies. According to the state of global water 
resources, $97 \%$ of the water on earth is seawater, which contains 3.0 to $5.0 \%$ salts [10-12]. If the seawater could be directly decomposed, the abundant seawater resources on Earth could be used as an economical, almost infinite, and environmentally friendly energy source.

Electrolysis generally consists of two half reactions, the oxygen evolution reaction (OER) and hydrogen evolution reaction (HER), which occur at the anode and cathode, respectively. Both reactions need highly efficient electrocatalysts to overcome energy consumption overpotentials. After a wide variety of research efforts and tremendous advancements, researchers have successfully developed many excellent electrocatalysts for OERs and HERs, which can significantly promote the application of water splitting [13-20]. However, electrocatalysts that are both stable and highly active are still insufficient to the task, so direct electrolysis of seawater to generate $\mathrm{H}_{2}$ remains challenging. For the HER at the cathode, the kinetics of HER are slow, which requires the electrocatalysts to have high conductivity. Another problem is that the microorganisms and insoluble precipitates present in natural seawater cover the active sites on the catalyst's surface, inhibiting HER performance. Although the electrolysis of water produces hydrogen at the cathode, it is strongly dependent on the efficiency and stability of the OER at the anode. For the OER, it involves a four-electron transfer process that inevitably leads to a high energy barrier and exhibits sluggish kinetics for seawater electrolysis. In addition, owing to the unavoidable presence of chloride ions in seawate $(0.5 \mathrm{M})$, the chloride evolution reaction (CER) also occurs at the anode at a relatively high electrochemical potential, in competition with the OER [21].

Chlorine oxidation is a multiplex reaction that varies according to several factors, such as the $\mathrm{pH}$ value of the electrolyte, temperature, potential, and so on [22]. Research on the selectivity of oxygen and chlorine has been taking place for decades. Developing electrocatalysts with high selectivity for OERs under high salinity has been a challenge $[23,24]$ that is usually ascribed to the linear scaling relationship between chlorine and oxygen adsorption energy. Although the OER possesses low thermodynamic redox potential $[25,26]$, it is not favorable in terms of kinetics as it involves the four-electrons transfer process. The reaction steps of OERs in alkaline, acidic and neutral electrolytes are shown below (Equations (1)-(8)).

Alkaline media:

$$
\begin{gathered}
\mathrm{OH}^{-} \rightarrow \mathrm{OH}^{*}+\mathrm{e}^{-} \\
\mathrm{OH}^{*}+\mathrm{OH}^{-} \rightarrow \mathrm{O}^{*}+\mathrm{H}_{2} \mathrm{O}+\mathrm{e}^{-} \\
\mathrm{O}^{*}+\mathrm{OH}^{-} \rightarrow \mathrm{HOO}^{*}+\mathrm{e}^{-} \\
\mathrm{HOO}^{*}+\mathrm{OH}^{-} \rightarrow \mathrm{O}_{2}(\mathrm{~g})+\mathrm{H}_{2} \mathrm{O}+\mathrm{e}^{-}
\end{gathered}
$$

Acidic and neutral media:

$$
\begin{gathered}
\mathrm{H}_{2} \mathrm{O} \rightarrow \mathrm{OH}^{*}+\mathrm{H}^{+}+\mathrm{e}^{-} \\
\mathrm{OH}^{*} \rightarrow \mathrm{O}^{*}+\mathrm{H}^{+}+\mathrm{e}^{-} \\
\mathrm{O}^{*}+\mathrm{H}_{2} \mathrm{O} \rightarrow \mathrm{HOO}^{*}+\mathrm{H}^{+}+\mathrm{e}^{-} \\
\mathrm{HOO}^{*} \rightarrow \mathrm{O}_{2}(\mathrm{~g})+\mathrm{H}^{+}+\mathrm{e}^{-}
\end{gathered}
$$

Figure 1 shows the diverse chlorine-containing products formed over the whole $\mathrm{pH}$ range [27]. The OER has a higher thermodynamic redox potential than the CER at all $\mathrm{pH}$ values. At parallel scales, a standard potential for hypochlorite formation is $480 \mathrm{mV}$ higher for the OER. The major preliminary products of chlorine-oxidation are chlorine gas, hypochlorous acid $(\mathrm{HOCl})$, and hypochlorite $\left(\mathrm{OCl}^{-}\right)$[28].

$$
2 \mathrm{H}_{2} \mathrm{O} \rightarrow 4 \mathrm{H}^{+}+\mathrm{O}_{2}+4 \mathrm{e}^{-}\left(\mathrm{E}^{\Theta}=1.229 \text { V vs. SHE, } \mathrm{pH}=0\right)
$$




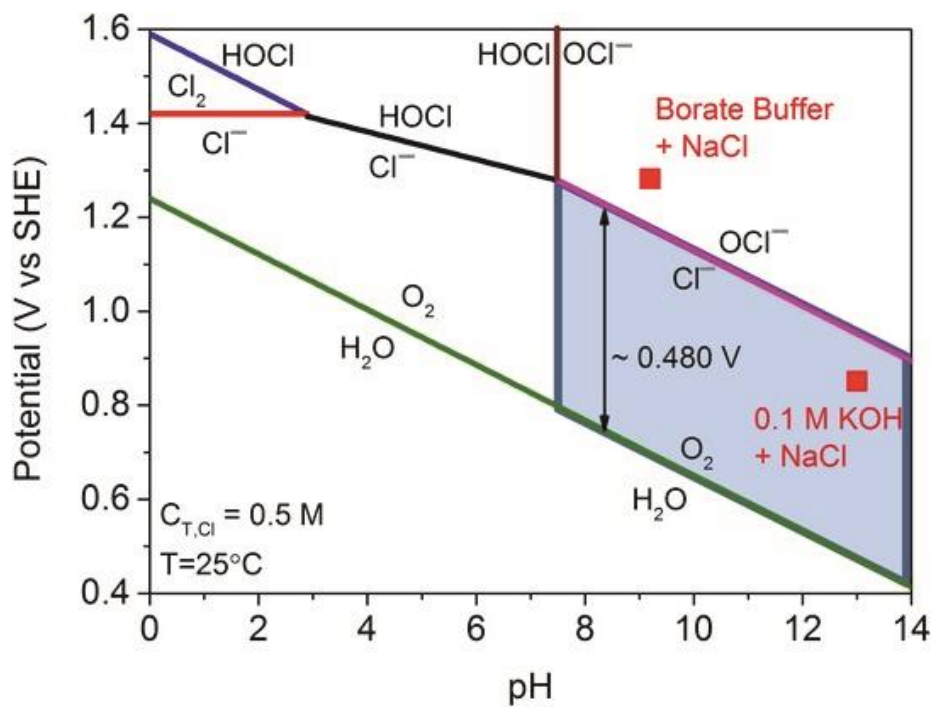

Figure 1. Pourbaix diagram for artificial seawater model [27]. Adapted with permission Ref. [27], Copyright 2016, Wiley-VCH.

The OER redox potential is $1.229 \mathrm{~V}$ vs. SHE (Equation (9)) at $\mathrm{pH}=0$, and it decreases to $0.76 \mathrm{~V}$ vs. SHE when in seawater at a $\mathrm{pH}$ value of 8 . The CER is independent of the $\mathrm{pH}$ value of seawater. It occurs at $1.358 \mathrm{~V}$ vs. SHE in seawater with an average $\mathrm{Cl}^{-}$ concentration of $0.55 \mathrm{M}$ (Equation (10)) [29].

$$
2 \mathrm{Cl}^{-} \rightarrow \mathrm{Cl}_{2}+2 \mathrm{e}^{-}\left(\mathrm{E}^{\Theta}=1.358 \text { V vs. SHE, } \mathrm{pH}=0\right)
$$

Formation of hypochlorous acid $(\mathrm{HOCl})$ and hypochlorite $\left(\mathrm{OCl}^{-}\right)$are dependent on the $\mathrm{pH}$ value of seawater. The thermodynamic balance of chlorine in an aqueous solution is very complicated because two harmful side reactions often occur, generating hypochlorous acid $(\mathrm{HOCl})$ at $\mathrm{pH}<7.46$ (Equation (11)) and hypochlorite ions $\left(\mathrm{ClO}^{-}\right.$) at $\mathrm{pH}>7.46$ (Equation (12)) $[26,28,30]$.

$$
\begin{aligned}
& \mathrm{Cl}^{-}+2 \mathrm{H}_{2} \mathrm{O} \rightarrow \mathrm{HOCl}+\mathrm{H}^{+}+2 \mathrm{e}^{-}\left(\mathrm{E}^{\theta}=1.48 \mathrm{~V} \text { vs. SHE }\right) \\
& \mathrm{Cl}^{-}+2 \mathrm{OH}^{-} \rightarrow \mathrm{ClO}^{-}+\mathrm{H}_{2} \mathrm{O}+2 \mathrm{e}^{-}\left(\mathrm{E}^{\theta}=1.57 \mathrm{~V} \text { vs. SHE }\right)
\end{aligned}
$$

These products are connected through chemical processes that occur in aqueous solutions. The formation of chlorine and hypochlorite is a two-electron process, and there is an immediate kinetics rivalry with the OER [31]. Designing and developing highly reactive and selective catalysts should be comprehensively considered to alleviate these thorny problems.

Therefore, the development of suitable OER electrocatalysts is crucial for the industrial application of direct seawater splitting. Recently, increasing efforts have been made to synthesizes OER electrocatalysts with high efficiency and selectivity. Therefore, it is necessary to thoroughly investigate and systematically summarize those electrocatalysts that have high selectivity and that exhibit anti-chlorine corrosion for OERs in seawater splitting, with the aim of indicating the prospects for performance improvement strategies. In this review, we classify highly selective electrocatalysts for OERs in seawater splitting, including both noble metal-based materials and non-noble metal-based materials. In order to ensure the prolonged operation of a seawater electrolysis system, we also focus on strategies to prevent seawater corrosion, for example, the development of inherent corrosion-resistant materials, surface protective coating methods, in situ electrochemical activation methods, and other anti-corrosion strategies. Moreover, the methods of asymmetric electrolyte feeds, proton exchange membrane (PEM) electrolysis, and solid oxide electrolysis cells (SOEC) also are discussed. 


\section{Electrocatalysts with High OER Selectivity}

\subsection{Noble Metal-Based Electrocatalysts}

Noble metal-based materials, such as Ir, Ru electrocatalysts, are recognized as being highly active electrocatalysts mainly due to their high intrinsic activity towards the OER as well as having more exposed active sites that are highly selective for OER in seawater splitting [32-35]. Based on the superior behavior and chemical stability of iridium in acid electrolytes, Ko and co-workers [34] prepared a train of iridium (Ir) metal-organic catalysts derived from high-surface activated carbon (AC) with an Ir loading of only $2-6 \mathrm{wt} \%$. These catalysts with low Ir loading still induced the organization of atoms with an Ir center (Figure 2a). In a synthetic electrolyte $\left(0.1 \mathrm{M} \mathrm{HClO}_{4}+3.5 \mathrm{wt} \% \mathrm{NaCl}\right), \mathrm{Cl}_{2}$ commenced to form at $1.4 \mathrm{~V}$ vs. RHE and reached a maximum concentration of $27 \mathrm{ppm}$ in the tested potential range (Figure $2 \mathrm{~b}$ ). The selectivity of this process in regard to OER is $21.9 \%$. When the catalyst was tested in synthetic seawater, no chlorine was detected (Figure $2 \mathrm{c}$ ) and the OER selectivity reached $98.5 \%$. In addition, Ir2 exhibits a low Toefl slopes of $92 \mathrm{mV} \mathrm{dec}{ }^{-1}$ and demonstrates $2 \mathrm{~h}$ stability under constant operating conditions (Figure 2d,e). Gayen et al. [35] reported a plumbum ruthenate pyrochlore $\left(\mathrm{Pb}_{2} \mathrm{Ru}_{2} \mathrm{O}_{7-\mathrm{x}}\right)$ electrocatalyst, with high levels of $\mathrm{Ru}(\mathrm{V})$ and oxygen vacancies, in neutral simulated seawater. It exhibited a higher OER activity and selectivity than did the benchmark $\mathrm{RuO}_{2}$. The authors analyzed the thermodynamics and kinetics of the chlorine species production reaction within a high $\mathrm{pH}$ environment, and experimentally verified that, under simulated seawater electrolysis, $\mathrm{Pb}_{2} \mathrm{Ru}_{2} \mathrm{O}_{7-\mathrm{x}}$ displayed superior OER selectivity ( $\sim 60$ times) at $\mathrm{pH}=13$ (approximately $99 \%$ ) than at $\mathrm{pH}=7$ (approximately 68\%). Although noble metal-based materials do exhibit excellent activity for OERs in seawater electrolysis, their wide application is still hindered by their limited reserves and high cost.
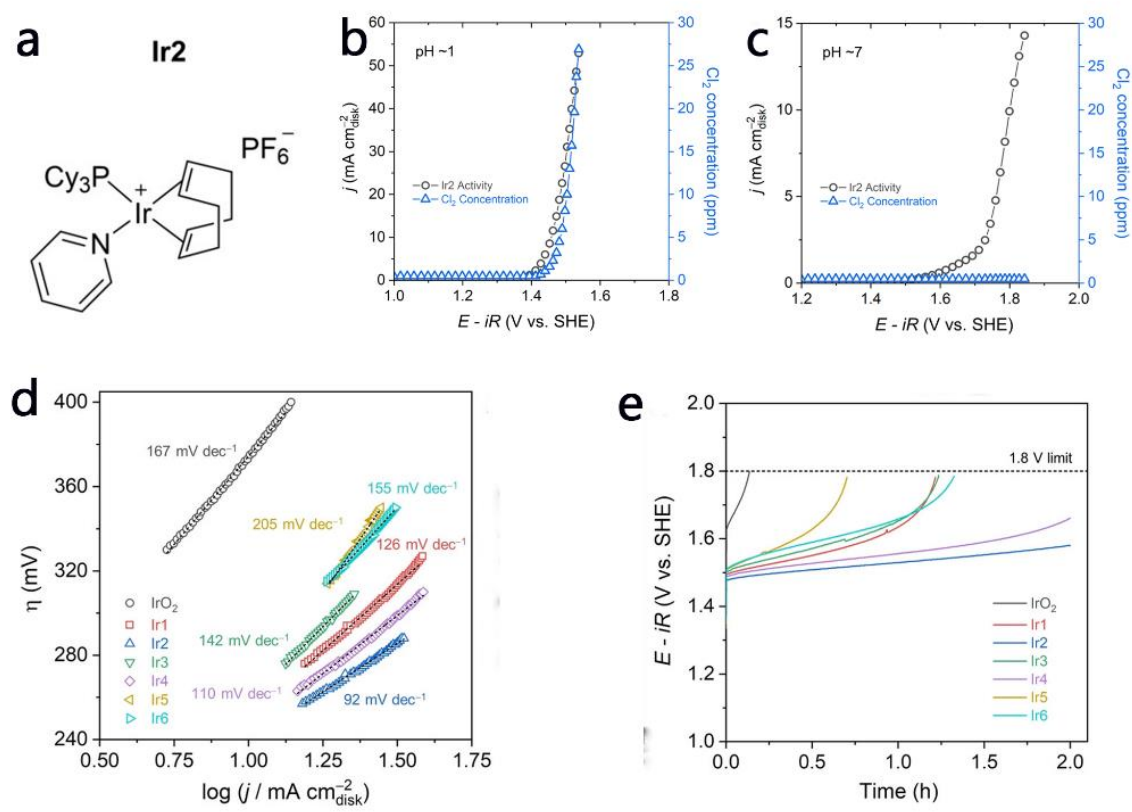

Figure 2. (a) Ir-based organometallics subject to pyrolysis with activated carbon: (1,5-cyclooctadiene) (pyridine)(tricyclohexylphosphine)-iridium(I) hexafluorophosphate [34]. The activity of the Ir catalyst and the concentration of produced $\mathrm{Cl}_{2}$ (b) at $\mathrm{pH}=1$ and (c) at $\mathrm{pH}=7$ (synthetic seawater) [34]. (d) Tafel slopes and (e) Stability tests of $\mathrm{IrO}_{2}$, and $\mathrm{Ir} 1-\mathrm{Ir} 6$ at $10 \mathrm{~mA} \mathrm{~cm}{ }^{-2}$ [34]. Adapted with permission Ref. [34], Copyright 2020, Wiley-VCH.

\subsection{Non-Noble Metal-Based Electrocatalysts}

It is imperative to exploit economical and high-activity materials as alternatives for noble metal-based catalysts. In recent years, non-noble metal electrocatalysts have been utilized for extensive OER research, including transition metal borides/carbides/nitrides / 
phosphides/oxides/chalcogenides, perovskites, and carbon materials. Transition metal alloys and their composites have generated widespread interest due to their capacity to balance price, performance, and durability. Great efforts and advances have been made to develop productive OER and HER electrocatalysts based on transition metal oxides (TMOs) $[36,37]$. Transition metal phosphides (TMPs) have been widely investigated as highefficiency dual-functional catalysts for seawater electrolysis in alkaline solutions because of their abundance in nature, simplicity of preparation, and glorious catalytic activity [38,39]. The reactivity and conductivity of these phosphides can be optimized by improving their electronic structure [40]. Ahn et al. [41] proposed that modified $\mathrm{Co}\left(\mathrm{PO}_{3}\right)_{2}$ nanoparticles with a nickel-type electrode can be used as the anode material for electrocatalysis. The catalytic reaction occurs at an overpotential of $\sim 310 \mathrm{mV}$. An oxygen detection experiment recorded that a Faradaic efficiency of $98 \pm 4 \%$ was obtained (within the experimental error range) at $\eta=440 \mathrm{mV}$, indicating that all currents are applicable for oxygen evolution.

Over the years of OER catalyst development, Ni-Fe layered double hydroxide (LDH) has proved to be one of the most promising OER electrocatalysts due to its outstanding OER performance and low cost. Dionigi et al. [42] targeted Ni-Fe hydroxide, when they proposed design standards and operating conditions for seawater electrolysis. NiFe LDH achieved $\sim 100 \%$ OER selectivity with a low overpotential $(<480 \mathrm{mV})$ in a simulated seawater electrolyte (Figure 3a,b). Cheng et al. [43] designed an electrocatalyst, with Co-Fe LDH (CF LDH) nanoparticles loaded on a Ti-mesh, for seawater electrolysis at a near-neutral $\mathrm{pH}$ condition. The CF LDH nanoparticles exhibited advantageous electrocatalytic activity $\left(\eta_{10}=530 \mathrm{mV}\right)$ and favorable selectivity for OERs in a simulated seawater electrolysis process. As shown in Figure 3c, a Faradaic efficiency of $94 \pm 4 \%$ was achieved at a constant overpotential. Very few hypochlorites were generated during the catalytic process, implying that the oxidation of water to $\mathrm{O}_{2}$ plays a major part in the CF LDH-sea salt system. Liu et al. [44] improved the electrocatalytic activity of CoFe-LDH/nickel foam (NF) by doping $\mathrm{Zr}^{4+}$ in CoFe-LDH/NF, which can adjust its electron configuration and expose plentiful sites for catalytic reactions. The integration of $\mathrm{Zr}^{4+}$ can tune the use of $\mathrm{O}$ intermediates, reduce the crystallinity, and extend the surface area, thus benefitting oxidation processes at low overpotentials. Song et al. [45] prepared ultrathin nanoplates of cobalt manganese LDH (CoMn LDH) with high reactivity and stability (Figure 3d). The intrinsic activity of a CoMn LDH catalyst is greater than that of the Co and Mn oxide nanoparticles. The oxygen yield during OERs using a CoMn LDH catalyst was quantified in a 5-h electrolysis experiment, measured with a fluorescence $\mathrm{O}_{2}$ detector (Figure 3e).

The formation of a protective layer on the reactive site of the anode material is a desirable method to effectively avoid chlorine oxidation reaction on the anode. Vos and colleagues [46] certified that coating $\mathrm{IrO}_{2}$ with a layer of $\mathrm{MnO}_{\mathrm{x}}$ can extensively enhance the selectivity of the OER. In an acid medium, $\mathrm{MnO}_{x} / \mathrm{IrO}_{x}$ showed nearly $100 \%$ OER selectivity since the $\mathrm{MnO}_{\mathrm{x}}$ layer successfully prevented the transport of chloride ions. However, this system cannot maintain efficient operation for a long time because the inactive $\mathrm{MnO}_{\mathrm{x}}$ layer blocks the active sites of the OER [46,47]. Okada et al. [47] then demonstrated that Mgintercalated $\delta-\mathrm{MnO}_{2}$ produces a superior improvement on OER selectivity. The preparation of a heterostructured catalyst, $\mathrm{Mg}$-intercalated Co-doped $\delta-\mathrm{MnO}_{2}\left(\mathrm{Mg} \mid \mathrm{Co}-\mathrm{MnO}_{2}\right)$ overlaid on $\alpha-\mathrm{Co}(\mathrm{OH})_{2}$, is shown in Figure 4a. It has been proven that this heterostructured catalyst preferentially yields oxygen. The permeation of $\mathrm{Cl}^{-}$can be effectively blocked by the overlayer of $\mathrm{Mg} \mid \mathrm{Co}-\mathrm{MnO}_{2}$ that can only transport water and oxygen, while the underlayer of $\alpha-\mathrm{Co}(\mathrm{OH})_{2}$ serves as an electrocatalyst for decomposing water transported from the upper layer. The interlayer space $(1 \times \infty)$ between the $\mathrm{MnO}_{2}$ layers acts as the pathway by which water molecules reach the active sites of $\mathrm{Co}(\mathrm{OH})_{2}$. Consequently, $\mathrm{Mg} / \mathrm{Co}-$ $\mathrm{MnO}_{2} / \mathrm{Co}(\mathrm{OH})_{2}$ delivered a supreme OER efficiency of $79 \%$ (Figure $4 \mathrm{~b}$ ). 
a

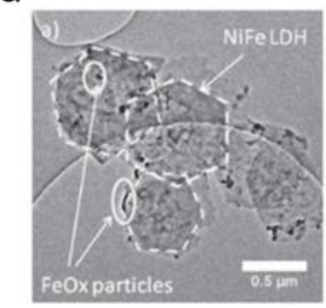

b

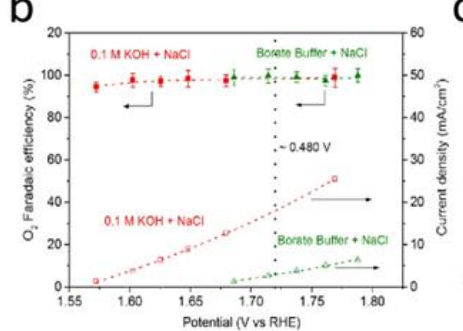

C

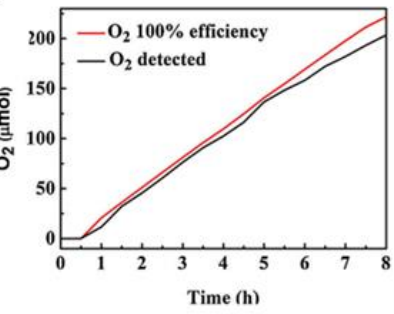

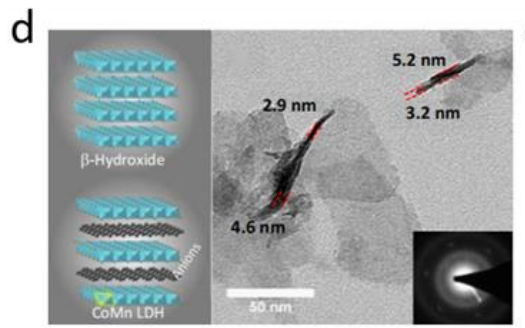

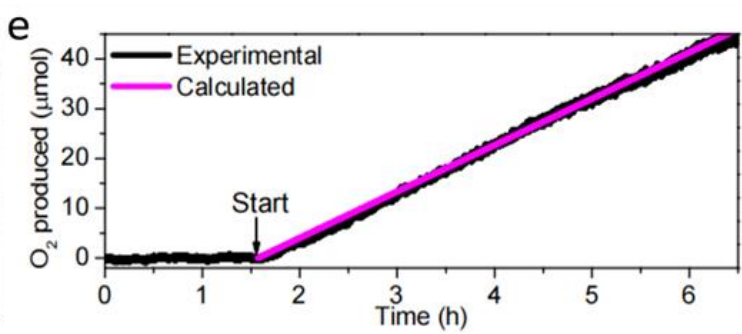

Figure 3. (a) TEM image of NiFe LDH nanoparticles [42]. (b) $\mathrm{O}_{2}$ Faradaic efficiency of NiFe LDH nanoparticles in $0.1 \mathrm{M} \mathrm{HClO}_{4}+3.5 \mathrm{wt} \% \mathrm{NaCl}$ [42]. (c) Faradaic efficiency of Co-Fe LDH catalyst in simulated seawater at a constant overpotential [43]. (d) Structure, TEM image, and (e) calculated and experimental oxygen production of CoMn LDH nanoplates [45]. Adapted with permission Ref. [42], Copyright 2016, Wiley-VCH. Ref. [43], Copyright 2017, Electrochimica Acta. Ref. [45], Copyright 2014, Journal of the American Chemical Society.

a

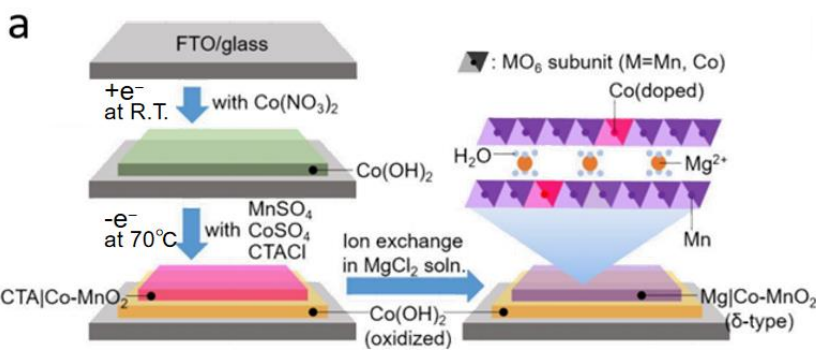

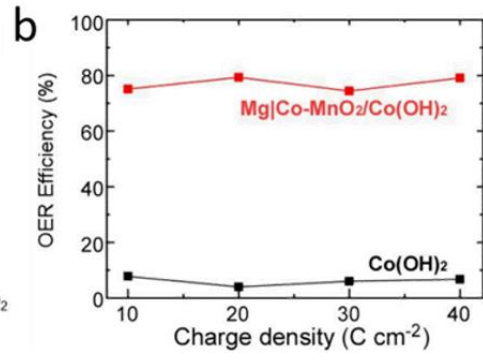

Figure 4. (a) Mechanism workflow chart of $\mathrm{Mg} \mid \mathrm{Co}-\mathrm{MnO}_{2}$ formation. (b) The relationship between the charge density and OER efficiency of $\mathrm{Mg} \mid \mathrm{Co}-\mathrm{MnO}_{2} / \mathrm{Co}(\mathrm{OH})_{2}$ [47]. Adapted with permission Ref. [47], Copyright 2020, American Chemical Society.

Three-dimensional (3D) porous metals have a high electrochemical surface area and exhibit advantageous electron/ion transfer. Hence, they have been attractive and effective electrodes for water splitting. For example, stainless steel is a prospective OER catalyst due to the existence of metal oxides and hydroxides on its surface, which can boost its catalytic properties $[48,49]$. However, the planar structure of stainless steel cannot achieve high catalytic performance on account of its low electrochemically-active surface area (ECSA) [50]. The porous 3D structure of stainless steel has received increasing attention in recent years because of its large ECSA and high porosity [51]. The application of 3D printing technology, without using any adhesive or additional processing, maximizes the OER activity of the electrode. Cellular stainless steel (CESS) manufactured by selective laser melting technology (Figure 5a) possesses high specific surface area and demonstrates superior mechanical performance [51]. More importantly, the prepared CESS electrode has good electrochemical activity, achieving an overpotential as low as $\sim 302 \mathrm{mV}$ at a current density of $10 \mathrm{~mA} \mathrm{~cm}^{-2}$ and a Tafel slope of only $43 \mathrm{mV} \mathrm{dec}^{-1}$ (Figure $5 \mathrm{~b}$ ). 
a

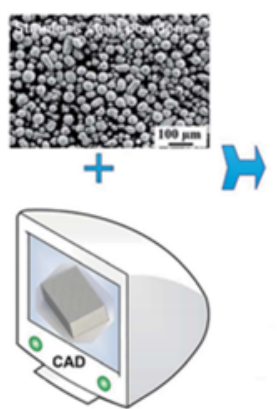

C

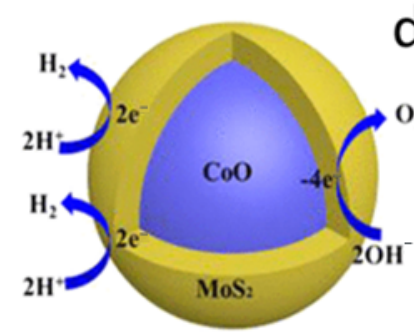

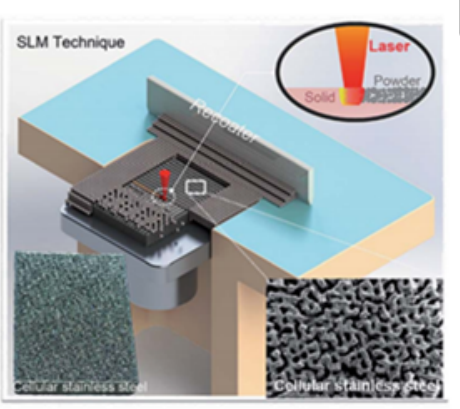

b

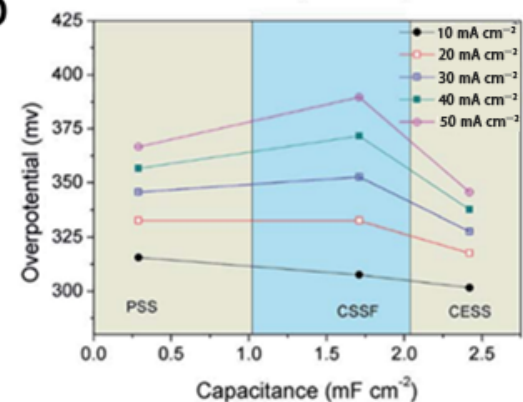

Capacitance $\left(\mathrm{mF} \mathrm{cm}^{-2}\right)$

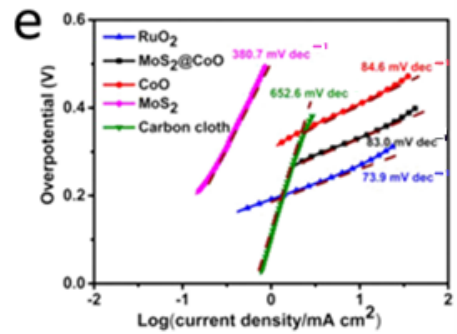

Figure 5. (a) Preparation process and (b) overpotential of CESS [51]. (c) OER mechanism, (d) TEM image, and (e) Tafel plots of $\mathrm{MoS}_{2} @ \mathrm{CoO}$ [52]. Adapted with permission Ref. [51], Copyright 2019, Royal Society of Chemistry. Ref. [52], Copyright 2019, American Chemical Society.

Core-shell nanostructured materials with synergistic effects have received widespread attention in electrochemical water splitting. Bifunctional core-shell structured $\mathrm{MoS}_{2} @ \mathrm{CoO}$ catalysts (Figure $5 \mathrm{c}$,d) have been investigated for seawater electrolysis in alkaline and neutral solutions [52]. The reported $\mathrm{MoS}_{2} @ \mathrm{CoO}$ consisted of a cobalt oxide nanocrystalline core wrapped in a $2 \mathrm{H}-\mathrm{MoS}_{2}$ nanosheet shell. This core-shell hybrid nanostructure significantly enhanced the electrocatalytic performance for OERs. For example, a low overpotential of $325 \mathrm{mV}$ at a current density of $10 \mathrm{~mA} \mathrm{~cm}^{-2}$ and a Tafel slope of $83 \mathrm{mV} \mathrm{dec}^{-1}$ were obtained in $1 \mathrm{M} \mathrm{KOH}$ solution, as shown in Figure 5e. For a clear comparison, we summarize the overpotential, Tafel slope, and selectivity of some representative electrocatalysts, as shown in Table 1.

Table 1. Electrocatalytic performance of well-developed electrocatalysts with high selectivity.

\begin{tabular}{|c|c|c|c|c|c|}
\hline Catalysts & Electrolyte & Overpotential $\eta(\mathrm{mV})$ & Tafel Slope $\left(\mathrm{mV} \mathrm{dec}{ }^{-1}\right)$ & Selectivity & Ref. \\
\hline Ir@AC & $0.1 \mathrm{M} \mathrm{HClO}_{4}+3.5 w \mathrm{t} \% \mathrm{NaCl}$ & $243 @ 10 \mathrm{~mA} \mathrm{~cm}^{-2}$ & 92 & $78.1 \%$ & [34] \\
\hline Ir @ AC & Synthetic seawater & $560 @ 10 \mathrm{~mA} \mathrm{~cm}^{-2}$ & / & $98.5 \%$ & [34] \\
\hline $\mathrm{Pb}_{2} \mathrm{Ru}_{2} \mathrm{O}_{7-\mathrm{x}}$ & Neutral seawater & $480 @ 10 \mathrm{~mA} \mathrm{~cm}{ }^{-2}$ & / & $68 \%$ & [53] \\
\hline $\mathrm{Pb}_{2} \mathrm{Ru}_{2} \mathrm{O}_{7-\mathrm{x}}$ & Alkaline seawater & $\sim 200 @ 10 \mathrm{~mA} \mathrm{~cm}^{-2}$ & / & $\sim 99 \%$ & [53] \\
\hline $\mathrm{Co}\left(\mathrm{PO}_{3}\right)_{2}$ & Phosphate-buffered water & $\sim 405 @ 10 \mathrm{~mA} \mathrm{~cm}{ }^{-2}$ & 74.1 & $98 \pm 4 \%$ & [41] \\
\hline $\mathrm{Ni}-\mathrm{Fe}$ LDH & Borate buffer $+\mathrm{NaCl}$ & $490 \pm 4 @ 10 \mathrm{~mA} \mathrm{~cm}^{-2}$ & $51 \pm 3$ & $\sim 100 \%$ & [42] \\
\hline Co-Fe LDH & Simulated seawater & $530 @ 10 \mathrm{~mA} \mathrm{~cm}-2$ & / & $94 \pm 4 \%$ & [43] \\
\hline Co-Fe-O-B & $1 \mathrm{M} \mathrm{KOH}+0.5 \mathrm{M} \mathrm{NaCl}$ & $294 @ 10 \mathrm{~mA} \mathrm{~cm}^{-2}$ & $52.6 \pm 0.4$ & $\sim 100 \%$ & [54] \\
\hline $\mathrm{MnO}_{\mathrm{x}} / \mathrm{IrO}_{\mathrm{x}}$ & Acidic saline water & $300 @ 5 \mathrm{~mA} \mathrm{~cm}{ }^{-2}$ & $\sim 43$ & $\sim 100 \%$ & [46] \\
\hline $\begin{array}{c}\mathrm{Mg} / \mathrm{Co}- \\
\mathrm{MnO}_{2} / \mathrm{Co}(\mathrm{OH})_{2}\end{array}$ & $\mathrm{MgCl}_{2}$ solution & / & 151 & $79.1 \%$ & [47] \\
\hline
\end{tabular}

\section{Anti-Chlorine Corrosion Electrocatalysts and Strategies}

Natural electrolytes are abundant in seawater, so corrosion is common. The phenomenon of seawater electrolytic corrosion greatly reduces the efficiency of seawater electrolysis and is the cause of huge economic losses. Accordingly, it is essential to investigate the corrosion behavior of the seawater electrolysis process and to take appropriate anticorrosion measures. More recently, an increasing number of catalysts are being reported 
for seawater splitting. Other than excellent reactivity, the electrocatalysts for seawater electrolysis also need to be corrosion-resistant and stable, especially to avoid any chemical reaction with $\mathrm{Cl}^{-}$in seawater. The chloride produced by CERs could destroy the oxide film on the surface of the metal (M) and form a passive layer on the surface. The inactive part is inclined to decompose into soluble chlorides due to the intense adsorption and permeability of $\mathrm{Cl}^{-}$(Equations (13) and (14)) [55,56].

$$
\begin{aligned}
& \mathrm{M}+\mathrm{Cl}^{-} \rightarrow \mathrm{M}^{-} \mathrm{Cl}_{\mathrm{ads}}+\mathrm{e}^{-} \\
& \mathrm{M}-\mathrm{Cl}_{\mathrm{ads}}+\mathrm{Cl}^{-} \rightarrow \mathrm{MCl}_{\mathrm{x}}{ }^{-}
\end{aligned}
$$

There are many essential factors that affect the corrosion rate, such as $\mathrm{Cl}^{-}$concentration, conductivity, hydrogen potential, and physical factors. In this section, we summarize some strategies to prevent the occurrence of seawater corrosion that has been reported in recent years. To ensure the prolonged safe operation of a seawater electrolysis system, firstly, a sensible choice of material is the most efficient aspect. The structure and properties of materials during the electrolysis process should be considered. Secondly, surface treatment and coating skills can be used to protect the boundary of metal materials and susceptible corrosive media. The surface coating can protect the internal structure from $\mathrm{Cl}^{-}$ corrosion. Thirdly, some specific reactions can in situ generate anti-corrosive species, which can circumvent the mass transfer resistance caused by the external protective layer. Finally, there are some special anti-corrosion approaches. For example, adding small amounts of chemicals to the corrosive medium is a convenient, quick, and inexpensive method [57,58].

\subsection{Inherent Corrosion-Resistant Electrocatalysts}

The higher the potential, the easier it is for the anode to be corroded. In high-salt circumstances, transition metals (e.g., Ti and $\mathrm{Ru}$ ) show excellent ability to withstand seawater corrosion [59,60], maintaining a sturdy framework during long-term electrolysis cycling. Ti-based materials have the characteristic of chlorine resistance. $\mathrm{IrO}_{2} / \mathrm{Ti}$ is a promising electrocatalyst for OERs in seawater splitting. For example, Yan et al. synthesized a series of $\gamma-\mathrm{MnO}_{2}$-type oxide electrodes based on an $\mathrm{IrO}_{2} / \mathrm{Ti}$ substrate via anodic deposition. The results demonstrated that the use of $\mathrm{Mn}-\mathrm{O}$ electrodes could lead to a sharp decrease in CERs and a significant increase in OERs. In particular, when adding Mo, V, and Fe elements to the electrode, the $\mathrm{Mn}+\mathrm{Mo}, \mathrm{Mn}+\mathrm{Mo}+\mathrm{V}$, and $\mathrm{Mn}+\mathrm{Fe}+\mathrm{V}$ oxide electrodes displayed oxygen evolution efficiencies of nearly $100 \%$ [61].

Besides the metal catalysts, the carbon-based substrate has a high electronic transfer rate and excellent tolerance to chloride ions, ensuring the efficiency of the integrated system. Dong et al. [62] synthesized Ni-Fe LDH nanosheet arrays supported on carbon fiber cloth (CC) (Figure 6a). The strong bond between the Ni-Fe LDH layer and the CC substrate gave the catalyst a high OER performance. The Faradaic efficiency of Ni-Fe $\mathrm{LDH} / \mathrm{CC}$ was determined to be $97.7 \%$ in $1 \mathrm{M} \mathrm{KOH}$ solution. Furthermore, in seawater electrolysis, the Faradaic efficiency of Ni-Fe LDH/CC was calculated to be as high as $96.9 \%$ and no chlorine was detected during this process (Figure 6b), indicating that the CER was completely suppressed. Song et al. [63] designed novel carbon-coated $\mathrm{Na}_{2} \mathrm{Co}_{1-\mathrm{x}} \mathrm{Fe}_{x} \mathrm{P}_{2} \mathrm{O}_{7}$ (NCFPO/C) nanoparticles as the OER electrocatalyst for an alkaline seawater electrolysis system (Figure 6c). Figure 6d,e show FESEM images of the CC before and after the dipcoating. It can be clearly observed that the NCFPO/C nanoparticles were uniformly loaded on the entire dip-coated CC. NCFPO/C@CC showed a favorable OER activity. More importantly, NCFPO/C@CC did not produce active chlorides that corrode the electrode in alkaline saline, exhibited a strong stability and endurance, and could continuously produce oxygen, as shown in Figure $6 f$. 

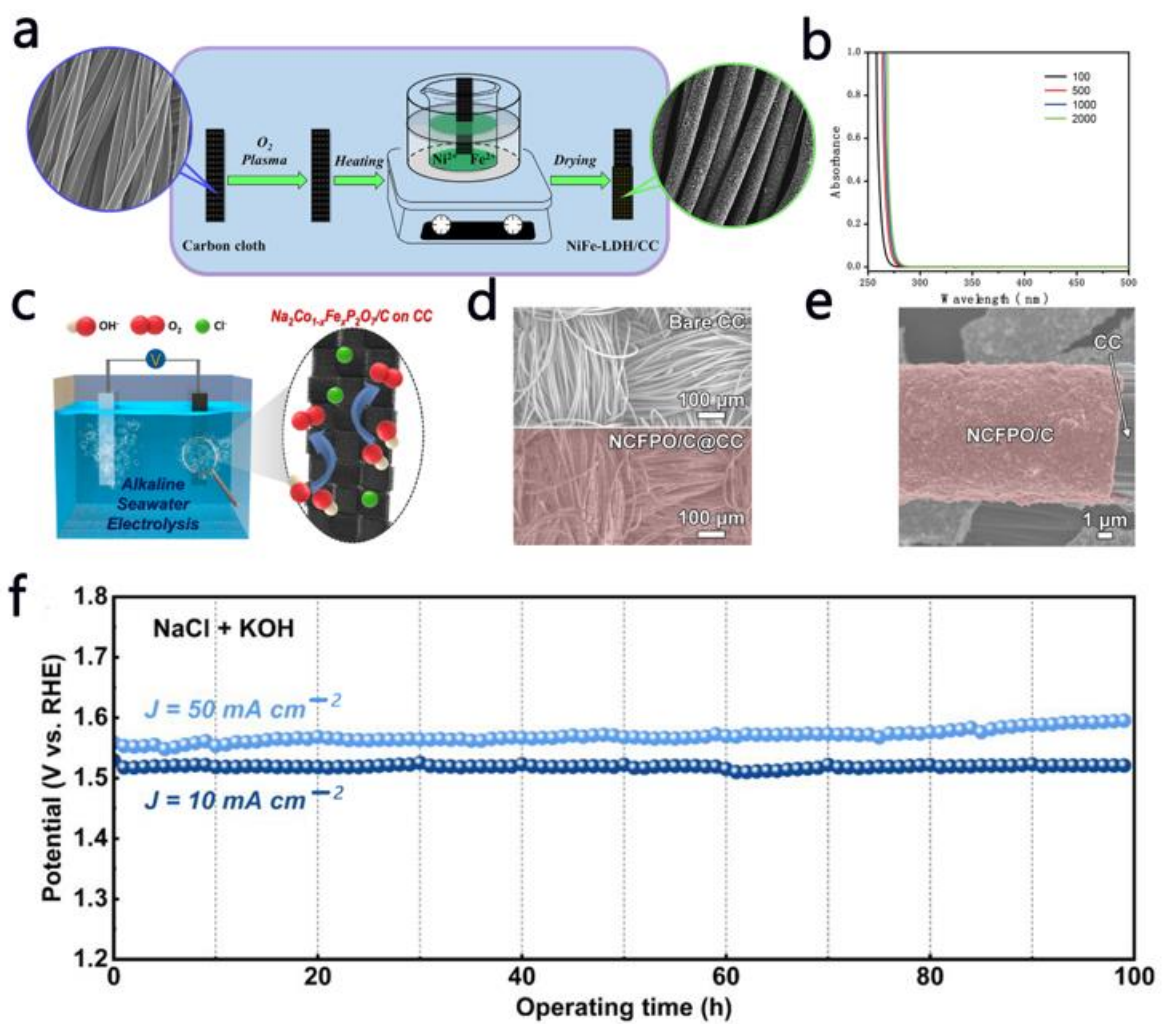

Figure 6. (a) Synthesis of NiFe LDH/CC. (b) UV-vis absorption spectra of electrolytes after the stability tests [62]. (c) Schematic diagram of OERs on an NCFPO/C@CC electrode [63]. FESEM images of (d) bare CC and (e) NCFPO/C@CC [63]. (f) Stability of NCFPO/C@CC [63]. Adapted with permission from Ref. [62], Copyright 2021, Elsevier Ltd.; Ref. [63], Copyright 2019, American Chemical Society.

The recent emergence of 2D transition metal carbides/nitrides, MXenes, has been reported due to their tremendous potential in corrosion resistance for seawater electrolysis. For instance, Qiu et al. [64] combined $\mathrm{Co}_{x} \mathrm{Mo}_{2-x} \mathrm{C} @ \mathrm{NG}$ composites with MXene, and the resulting catalyst exhibited significant durability ( $225 \mathrm{~h}), 64$ times that of Pt/C. Additionally, the reaction's Faradaic efficiency reached $98 \%$.

\subsection{Surface Treatment and Coating Strategy}

Surface coating is one of the common methods used to protect electrocatalysts from corrosion during water electrolysis [65]. Luo et al. reported a 3D core-shell electrocatalyst NiMoN@NiFeN supported on Ni foam. The synthesis procedure for the catalyst is demonstrated in Figure 7a. Scanning electron microscope (SEM) images in Figure 7b-d show that NiFeN nanoparticles were uniformly distributed on the smooth surface of the NiMoN vertical bar, which was grown on Ni foam. The presence of NiFeN nanoparticles on the NiMoN surface during OER tests not only promoted the OER activity but also was beneficial for corrosion resistance. During electrolysis in alkaline simulated seawater $(1 \mathrm{M} \mathrm{KOH}+0.5 \mathrm{M} \mathrm{NaCl})$, only $\mathrm{H}_{2}$ and $\mathrm{O}_{2}$ were detected, with no chloride gases being found and the Faradaic efficiency being about $97.8 \%$ [66]. 

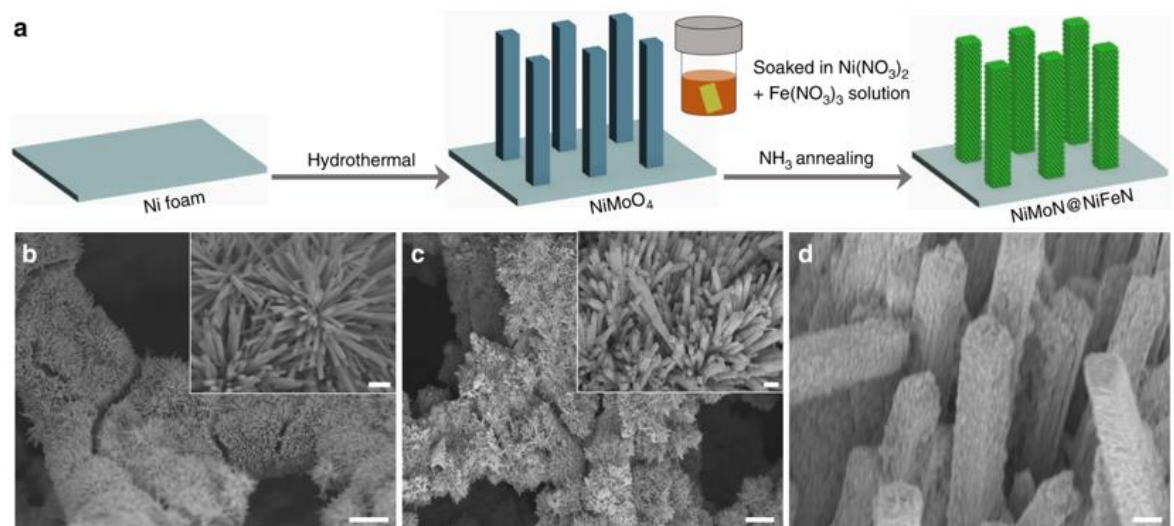

e

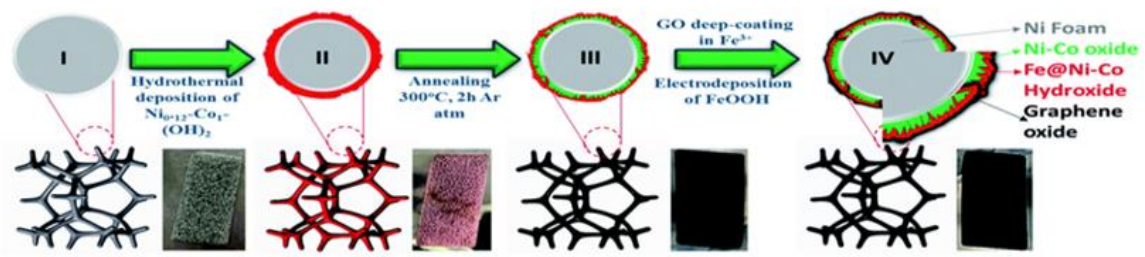

Figure 7. (a) Schematic image of the synthesis procedure for the NiMoN@NiFeN catalyst [66]. SEM images of (b) NiMoN and (c,d) NiMoN@NiFeN with scale bars of $30 \mu \mathrm{m}$, insets $3 \mu \mathrm{m}$ [66]. (e) Schematic illustration of the preparation process [67]. Adapted with permission from Ref. [66], Copyright 2019, Springer Nature. Ref. [67], Copyright 2020, Royal Society of Chemistry.

So far, different kinds of catalyst support have been manufactured, like carbon black, carbon nanofibers, metal oxides, and so on [68]. Graphene's atomic layer is in the shape of a sp ${ }^{2}$ C-bonded 2D nanosheet [69], which is regarded as a promising support material for metal catalysts. Graphene is applied as an anti-corrosion coating additive owing to its strong stability and high mechanical strength, as well as unique characteristics such as chemical inertness, impermeability, and excellent thermal and chemical stability [70-75]. Various methods can be used to prepare graphene-based anti-corrosion coatings, such as chemical vapor deposition, spin coating, the sol-gel approach, in situ polymerization, and so on. Among these, graphene grown by chemical vapor deposition (CVD-graphene) is an excellent protective coating for metals that can prevent metal corrosion due to electrochemistry, heat, or humidity [76-79]. Jadhav et al. [67] reported a novel vibrant catalyst: $\mathrm{FeOOH}$ deposited onto $\mathrm{Ni}$-Co hydroxide with an external graphene oxide protective layer (Figure 7e). The gas produced from the anode side was detected through gas chromatography (GC), the result revealing that only $\mathrm{O}_{2}$ was detectable. Using the o-tolidine test, it was shown that no liquid phase chloride oxide, such as $\mathrm{HClO}$ or $\mathrm{ClO}^{-}$, was formed during the constant current OER testing. The authors proved that the presence of oxygen functional groups in graphene oxide promoted changes in chemical properties and improved corrosion inhibition. The pure graphene-based coating can validly isolate the corrosive medium from the electrode material. However, it may also accelerate the corrosion of the underlying metal. Graphene composite materials can solve this problem well. The graphene composite not only has better corrosion resistance than traditional coatings, but it does not destroy the structure of graphene [80]. Therefore, it is a very promising anti-corrosion coating material.

\subsection{In Situ Electrochemical Activation Strategy}

To a certain extent, the protective layer on the surface can prevent the electrode from corroding. However, when the protective layer plays a role in blocking the transport of chloride ions, it also increases the mass transfer resistance of the catalytic reaction. The in situ generation of resistant species through surface oxidation and reconstruction is an effective way to address this issue [81-85]. Based on this, advanced bifunctional electrocatalysts, i.e., $\mathrm{NiFe} \mathrm{LDH} / \mathrm{FeOOH}$ heterostructured nanosheets (Figure 8a), were 
reported to prevent seawater electrolytic corrosion [84]. The heterostructure of NiFe $\mathrm{LDH} / \mathrm{FeOOH}$ can promote the production of active $\mathrm{NiOOH}$ species during the reaction process. Due to the strong interaction between FeOOH and NiFeLDH, and the shape of $\mathrm{NiOOH}$, it not only resists corrosion due to $\mathrm{Cl}^{-}$, but also forms a strong coupling between the two phases to improve electrochemical reactivity and stability. The polarization curves of $\mathrm{NiFe} \mathrm{LDH} / \mathrm{FeOOH}$ for OERs in alkaline simulated seawater splitting are shown in Figure $8 \mathrm{~b}$. When NiFe LDH/FeOOH was used as both the cathode and anode, it exhibited excellent long-term operational stability, and operated for $105 \mathrm{~h}$ at a large current density of $100 \mathrm{~mA} \mathrm{~cm}^{-2}$.

a

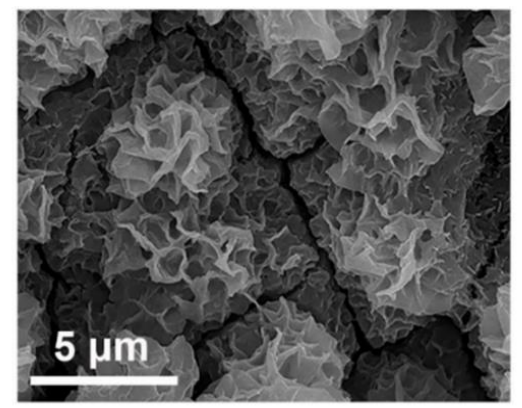

c

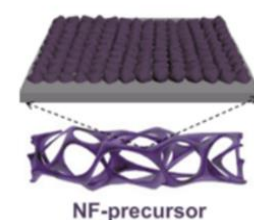

NF-precursor

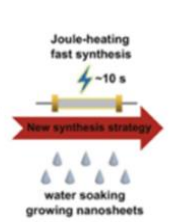

growing nanosheots

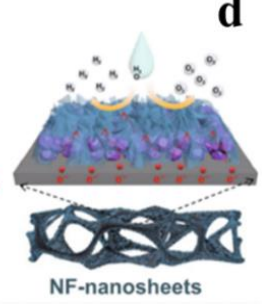

d b
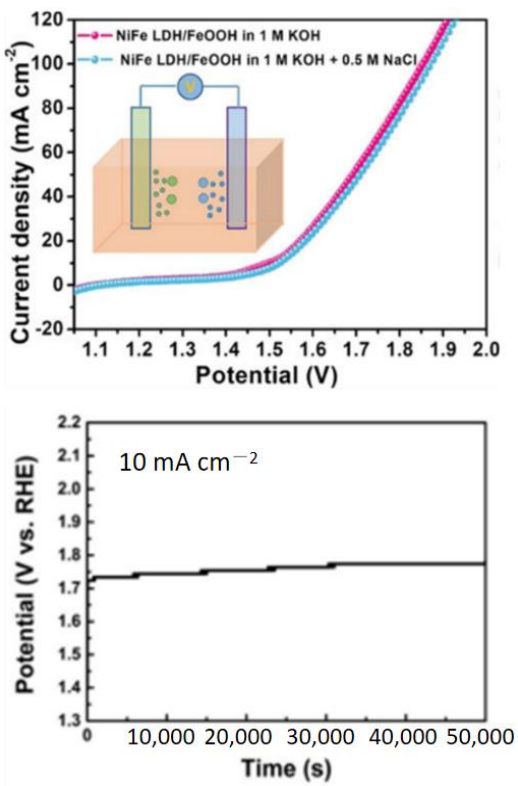

Figure 8. (a) SEM image of NiFe LDH/FeOOH sample after the OER [84]. (b) Polarization curves of $\mathrm{NiFe} \mathrm{LDH} / \mathrm{FeOOH}$ for water splitting and alkaline simulated seawater splitting [84]. (c) Synthetic schematic of thin carbon-coated CoS on NF (NF-C/CoS) [85]. (d) Chronopotentiometry curve of NF$\mathrm{C} / \mathrm{CoS} / \mathrm{NiOOH}$ [85]. Adapted with permission from Ref. [84], Copyright 2021, American Chemical Society. Ref. [85], Copyright 2020, Springer.

Nickel foam (NF) has been extensively used in the field of energy conversion and storage. Wu et al. [85] first synthesized thin carbon-coated CoS on NF (NF-C/CoS) after rapid cooling by Joule heating, and then prepared NF-C/CoS/NiOOH with a core-shell heterostructure by utilizing the reaction of the metastable $\mathrm{Ni}$ with water to form $\mathrm{NiOOH}$ nanosheets and C/CoS "seeds", thus inducing spontaneous and continuous growth of $\mathrm{NiOOH}$ nanosheets (Figure 8c). As a self-supporting electrocatalyst, $\mathrm{NF}-\mathrm{C} / \mathrm{CoS} / \mathrm{NiOOH}$ exhibited favorable oxidation reaction performance and good stability for $50,000 \mathrm{~s}$ in the overall water splitting test (Figure $8 \mathrm{~d}$ ). This feat contributes a new preparation method for NF-based nanomaterials and opens new development directions in the field of catalysis.

\subsection{Other Strategies}

In addition to the above three methods to solve the problem of seawater electrolytic corrosion, the following methods also provide us with new ideas for the prevention of seawater corrosion. Contrary to the huge efforts recently invested in the development of highly active electrocatalysts, several works have concentrated on the design of electrolytes thus far. Li and co-workers [86] used the common ion effect, that is, increasing $\mathrm{NaOH}$ can decrease the saturation concentration of $\mathrm{NaCl}$, to inhibit the concentration of chloride ions, which can halve the solubility of $\mathrm{NaCl}$ in the electrolyte, resulting in $\mathrm{NaCl}$ crystallization. This method greatly suppressed both corrosion and CERs at the anode during the electrolysis of seawater (Figure 9a). In the simulation and calcium-magnesium-free seawater electrolysis system, the ternary NiCoFe phosphide can remain active for more than $100 \mathrm{~h}$ 
(Figure 9b). Furthermore, when applying a Nafion membrane, the rate of generation of $\mathrm{NaCl}$ crystals can be increased by six times owing to the transmission of sodium ions from the anode to the cathode through the Nafion membrane. This provides an idea for the design of a functional electrolyte for seawater electrolysis in the future.

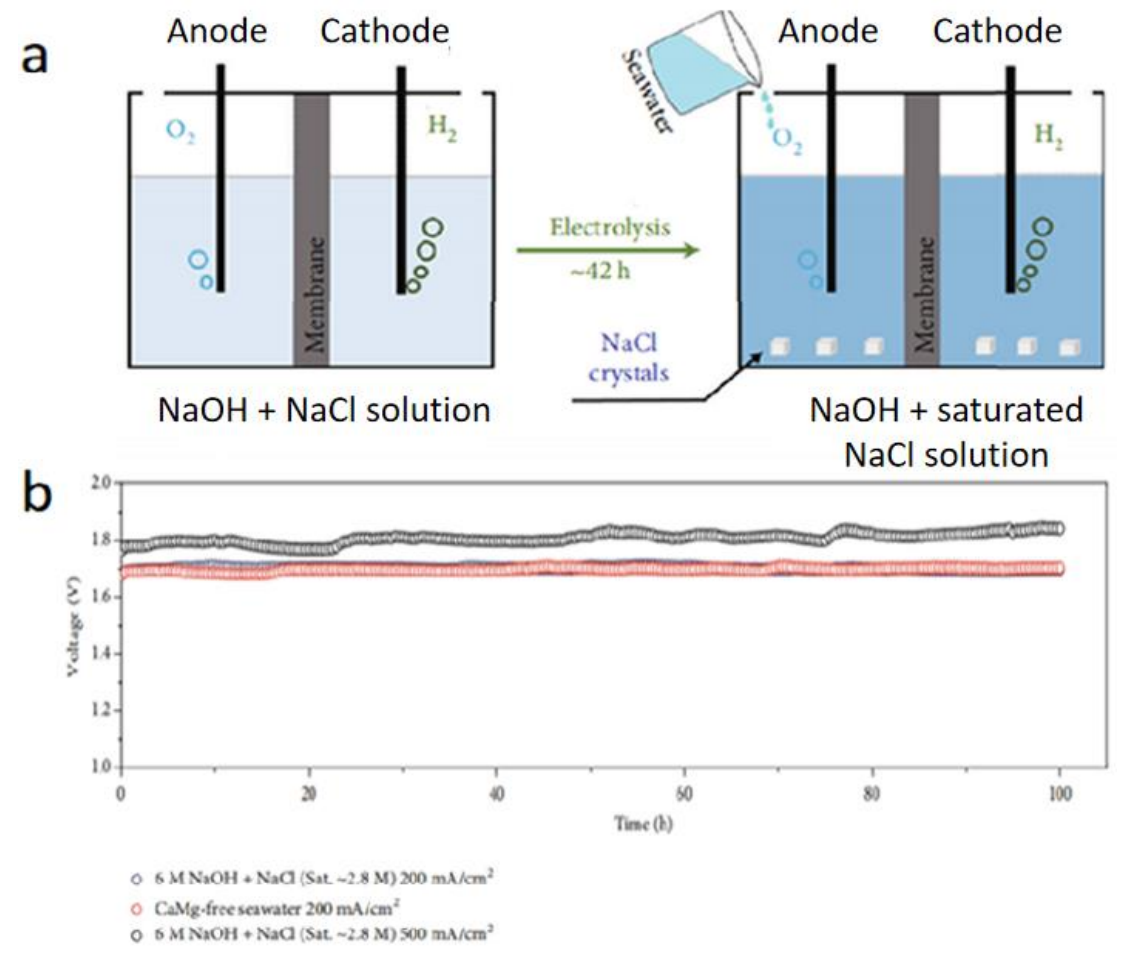

Figure 9. (a) Schematic diagram of the common-ion effect to enhance electrochemical catalytic performance. (b) Chronopotentiometry curve of ternary NiCoFe phosphide under three electrolytes [86]. Adapted with permission from Ref. [86], Copyright 2020, Research (Wash DC).

Dresp et al. [87] proposed the concept of asymmetric electrolyte feeds. Neutral seawater is directly injected into the cathode, while a high-purity $\mathrm{KOH}$ electrolyte is circulated at the anode. In an alkaline electrolyte containing $\mathrm{Cl}^{-}$, a NiFe-LDH anode catalyst still has complete selectivity in regard to OERs without any $\mathrm{Cl}^{-}$oxidation, which allows it to operate continuously and stably under high voltage and current density.

PEM water electrolysis is one of the most promising technologies for high-purity and high-efficiency hydrogen production under high dynamic operating conditions without any carbon emissions $[88,89]$. In addition, the application of a PEM can enhance the corrosion resistance of a seawater electrolysis system. For instance, Rossi et al. [90] used the charge repulsion of a PEM to chloride ions to reduce the generation of chlorine. The evolution of chlorine was dramatically inhibited when introducing a humidified air stream to the anode in a saltwater electrolyte. Moreover, the $\mathrm{pH}$ value of the electrolyte in the overall cell could be commendably regulated due to the strengthened proton migration caused by the electric field. Consequently, the sodium ion transportation could be minimized without a liquid anolyte. In synthesized brackish water, anodic Faradaic efficiencies for oxygen evolution were nearly $100 \%$.

Solid oxide electrolysis cells (SOECs), operating at high temperatures, can evaporate seawater into salt-free pure water vapor, as shown in Figure 10a. Nowadays, the SOEC is considered to be an excellent candidate for seawater splitting due to its remarkable stability, which can prevent any undesirable effects of the high salinity of the electrolytes. However, in the SOEC system, it is still necessary to find materials that can operate stably in high temperature environments. Furthermore, it is urgent to solve the problem of energy hunger due to the heating and evaporation of seawater. Liu and co-workers [91] evaluated the 
productivity and stability of this electrolysis method by splitting natural seawater. The content of water vapor in the electrolysis solution system can be controlled by changing the temperature. Hydrogen introduced into the electrode (not consumed during electrolysis) can protect $\mathrm{Ni}$ from oxidation. Reduction of nickel oxide to metallic nickel can be realized at the electrode (Figure 10b). High energy conversion productivity and a low cell degradation rate were achieved at a constant current density for $420 \mathrm{~h}$ (Figure 10c). However, the partial sea salt sediments that were detected in the air intake tube will be a primary barrier to the long-term operation of the system.
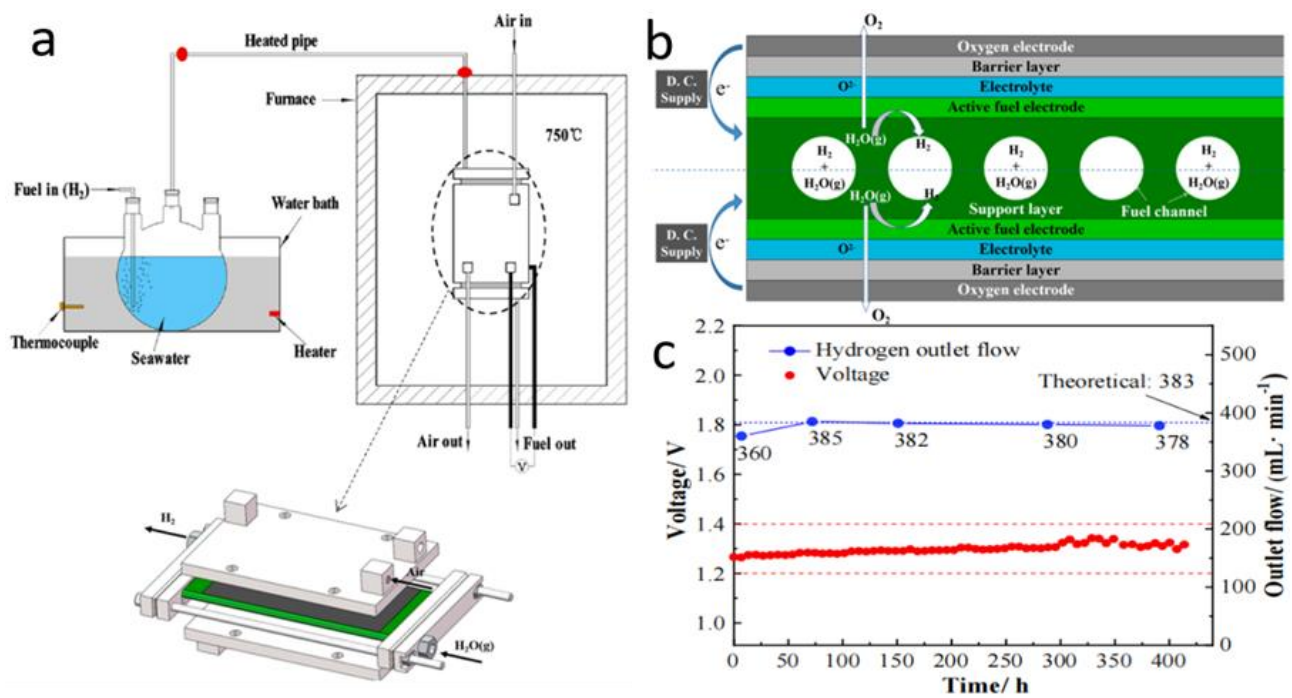

Figure 10. Schematic diagrams of (a) SOEC device and (b) water electrolysis process in an SOEC. (c) Chronopotentiometry curve of LSCF $\left(\mathrm{La}_{0.6} \mathrm{Sr}_{0.4} \mathrm{Co}_{0.2} \mathrm{Fe}_{0.8} \mathrm{O}_{3}\right)$ in natural seawater electrolytes [91]. Adapted with permission from Ref. [91], Copyright 2021, Elsevier.

\section{Conclusions and Perspectives}

The ocean on the Earth can supply nearly inexhaustible seawater, which can be treated as an abundant and economic hydrogen source. For the commercial and large-scale production of hydrogen, direct seawater electrolysis provides a promising method. However, chlorine corrosion and oxidation due to the inevitable presence of chloride ions in seawater seriously impedes the utilization of this technology. Over decades, a tremendous amount of research has been conducted on material modifications and structural optimization of electrocatalysts. In this review, we summarized five different types of material for highly selective seawater splitting and introduced several effective anti-corrosion strategies. A seawater electrolysis OER catalyst needs low overpotential, long-term stability, and $\mathrm{Cl}^{-}$corrosion resistance. Here, we provided several design strategies for seawater splitting: (1) An LDH layer can be deposited or grown on a conductive substrate with large specific surface area (such as Ni Foam), and then modified to obtain the desired seawater electrolysis OER electrode material. Combined with the high conductivity of the sublayer, the LDH layer structure could enhance electron, which would contribute to high OER activity. (2) Designing 3D hierarchical porous nano-architectures is an effective strategy for increasing surface area and improving mass transport. (3) A protective layer with some anti-corrosion materials deposited on the catalyst's surface can block $\mathrm{Cl}^{-}$ions. However, this protective layer may result in sluggish mass transport, thus damaging the catalyst's activity. The selection and preparation of the coating layer requires elaborate design.

Although some remarkable results have been achieved, there are still some important issues that need to be addressed in the future. The issues and possible solutions are listed below: 
(1) Selection of materials with high selectivity and anti-corrosion properties. Based on data for potential candidate materials provided by previous studies, the technology of artificial intelligence could be investigated as an efficient and convenient screening approach.

(2) Evaluation of anti-corrosion strategies. Electrocatalytic surface modification and structure optimization are effective methods for the fabrication of anti-corrosion materials. In situ-generated anti-corrosive species can avoid the mass transfer resistance caused by the external protective layer.

(3) Novel integrated electrolytic cell unit. Reasonable design of electrolytic cells may improve the overall reaction efficiency.

(4) High-temperature electrolysis. SOECs could be the next-generation electrolyzers for direct seawater splitting.

(5) Due to several difficulties when using seawater directly, the preliminary desalination of sea water may be another choice.

In summary, the current research in this field is still limited. The development of electrocatalysts that have high selectivity and distinguished performance against chlorine corrosion during direct seawater electrolysis requires urgent attention.

Author Contributions: Conceptualization, Z.S., C.S. and S.J.; validation, S.J., Y.L. and H.Q.; data curation, C.S.; writing —original draft preparation, S.J., Y.L. and H.Q.; writing-review and editing, C.S. and S.J.; supervision, C.S. and S.J.; project administration, Z.S.; funding acquisition, C.S. and S.J. All authors have read and agreed to the published version of the manuscript.

Funding: This research was funded by the Natural Science Foundation of the Jiangsu Higher Education Institutions of China (Grant No. 2018ND133J) and the Natural Science Foundation of Jiangsu Province, China (Grant No. BK20190965).

Institutional Review Board Statement: Not applicable.

Informed Consent Statement: Not applicable.

Data Availability Statement: Not applicable.

Acknowledgments: This research was financially supported by the Natural Science Foundation of the Jiangsu Higher Education Institutions of China (Grant No. 2018ND133J) and the Natural Science Foundation of Jiangsu Province, China (Grant No. BK20190965).

Conflicts of Interest: The authors declare no conflict of interest.

\section{References}

1. Formal, F.; Bouree, W.; Prevot, M.; Sivula, K. Challenges towards economic fuel generation from renewable electricity: The heed for efficient electro-catalysis. Chimia 2015, 69, 789-798. [CrossRef] [PubMed]

2. Fukuzumi, S.; Lee, Y.; Nam, W. Fuel Production from seawater and fuel cells using seawater. ChemSusChem 2017, 10, 4264-4276. [CrossRef] [PubMed]

3. Zhu, Z.; Wan, S.; Zhao, Y.; Gu, Y.; Wang, Y.; Qin, Y.; Zhang, Z.; Ge, X.; Zhong, Q.; Bu, Y. Recent advances in bismuthbased multimetal oxide photocatalysts for hydrogen production from water splitting: Competitiveness, challenges, and future perspectives. Mater. Rep. Energy 2021, 1, 100019. [CrossRef]

4. Hausmann, J.; Schlogl, R.; Driess, M.; Hausmann, J.; Schlögl, R.; Menezes, P.; Driess, M. Is direct seawater splitting economically meaningful? Energy Environ. Sci. 2021, 7, 3679-3685. [CrossRef]

5. Yang, H.; Driess, M.; Menezes, P. Self-supported electrocatalysts for practical water electrolysis. Adv. Energy Mater. 2021, 11, 2102074. [CrossRef]

6. Yao, Y.; Gao, X.; Meng, X. Recent advances on electrocatalytic and photocatalytic seawater splitting for hydrogen evolution. Int. J. Hydrogen Energy 2021, 46, 9087-9100. [CrossRef]

7. Farràs, P.; Strasser, P.; Cowan, A. Water electrolysis: Direct from the sea or not to be? Joule 2021, 5, 1921-1923. [CrossRef]

8. Badreldin, A.E.; Abusrafa, A.; Abdel-Wahab, A. Oxygen-deficient cobalt-based oxides for electrocatalytic water splitting. ChemSusChem 2021, 14, 10-32. [CrossRef]

9. Peng, J.; Dong, W.; Wang, Z.; Meng, Y.; Liu, Z. Recent advances in 2D transition metal compounds for electrocatalytic full water splitting in neutral media. Mater. Today Adv. 2020, 8, 100081-100098. [CrossRef]

10. Wang, C.; Shang, H.; Jin, L.; Xu, H.; Du, Y. Advances in hydrogen production from electrocatalytic seawater splitting. Nanoscale 2021, 13, 7897-7912. [CrossRef] 
11. Ke, S.; Chen, R.; Ma, X. Mini review on electrocatalyst design for seawater splitting: Recent progress and perspectives. Energy Fuels 2021, 35, 12948-12956. [CrossRef]

12. Zhang, F.; Yu, L.; Ren, Z. Rational design of oxygen evolution reaction catalysts for seawater electrolysis. Trends Chem. 2021, 3, 485-498. [CrossRef]

13. Bolar, S.; Shit, S.; Kuila, T. Progress in theoretical and experimental investigation on seawater electrolysis: Opportunities and challenges. Sustain. Energy Fuels 2021, 5, 5915-5945. [CrossRef]

14. Khatun, S.; Hirani, H.; Roy, P. Seawater electrocatalysis: Activity and selectivity. J. Mater. Chem. A 2021, 9, 74-86. [CrossRef]

15. Yu, J.; Dai, Y.; He, Q.; Zhao, D.; Shao, Z.; Ni, M. A mini-review of noble-metal-free electrocatalysts for overall water splitting in non-alkaline electrolytes. Mater. Rep. Energy 2021, 1, 100024. [CrossRef]

16. Su, C.; Wang, W.; Shao, Z. Cation-deficient perovskites for clean energy conversion. Acc. Mater. Res. 2021, 2, 477-488. [CrossRef]

17. Su, C.; Wang, W.; Chen, Y.; Yang, G.; Xu, X.; Tadé, M.O.; Shao, Z. SrCo ${ }_{0.9} \mathrm{Ti}_{0.1} \mathrm{O}_{3-\delta}$ as a new electrocatalyst for the oxygen evolution reaction in alkaline electrolyte with stable performance. ACS Appl. Mater. Interfaces 2015, 7, 17663-17670. [CrossRef] [PubMed]

18. She, S.; Zhu, Y.; Wu, X.; Hu, Z.; Shelke, A.; Pong, W.; Chen, Y.; Song, Y.; Liang, M.; Chen, C.; et al. Realizing high and stable electrocatalytic oxygen evolution for iron-based perovskites by co-doping-induced structural and electronic modulation. Adv. Funct. Mater. 2021, 2111091. [CrossRef]

19. Xu, X.; Sun, H.; Jiang, S.; Shao, Z. Modulating meta-organic frameworks for catalyzing acidic oxygen evolution for proton exchange membrane water electrolysis. SusMat 2021, 1, 460-481. [CrossRef]

20. Xu, X.; Pan, Y.; Ge, L.; Chen, Y.; Mao, X.; Guan, D.; Li, M.; Zhong, Y.; Hu, Z.; Peterson, V.K.; et al. High-performance perovskite composite electrocatalysts enabled by controllable interface engineering. Small 2021, 17, 2101573. [CrossRef]

21. Dresp, S.; Dionigi, F.; Klingenhof, M.; Strasser, P. Direct electrolytic splitting of seawater: Opportunities and challenges. ACS Energy Lett. 2019, 4, 933-942. [CrossRef]

22. Tong, W.; Forster, M.; Dionigi, F.; Dresp, S.; Erami, R.; Strasser, P.; Cowan, A.; Farras, P. Electrolysis of low-grade andsaline surface water. Nat. Energy 2020, 5, 367-377. [CrossRef]

23. Izumiya, K.; Akiyama, E.; Habazaki, H.; Kumagai, N.; Kawashima, A.; Hashimoto, K. Anodically deposited manganese oxide and manganese-tungsten oxide electrodes for oxygen evolution from seawater. Electrochim. Acta 1998, 43, 3303-3312. [CrossRef]

24. Trasatti, S. Electrocatalysis in the anodic evolution of oxygen and chlorine. Electrochim. Acta 1984, 29, 1503-1512. [CrossRef]

25. Hansen, H.; Man, I.; Studt, F.; Abild-Pedersen, F.; Bligaard, T.; Rossmeisl, J. Electrochemical chlorine evolution at rutile oxide (110) surfaces. Phys. Chem. Chem. Phys. 2010, 12, 283-290. [CrossRef]

26. Exner, K.; Anton, J.; Jacob, T.; Over, H. Controlling selectivity in the chlorine evolution reaction over $\mathrm{RuO}_{2}$-based catalysts. Angew. Chem. Int. Ed. Engl. 2014, 126, 11212-11215.

27. Crittenden, J.C.; Trussell, R.R.; Hand, D.W.; Howe, K.J.; Tchobanoglous, G. MWH's Water Treatment: Principles and Design, 3rd ed.; John Wiley \& Sons Ltd.: Hoboken, NJ, USA, 2012.

28. Karlsson, R.; Cornell, A. Selectivity between oxygen and chlorine evolution in the chlor-alkali and chlorate processes. Chem. Rev. 2016, 116, 2982. [CrossRef]

29. Abe, H.; Murakami, A.; Tsunekawa, S.; Okada, T.; Wakabayashi, T.; Yoshida, M.; Nakayama, M. Selective catalyst for oxygen evolution in neutral brine electrolysis: An oxygen-deficient manganese oxide film. ACS Catal. 2021, 11, 6390-6397. [CrossRef]

30. Amikam, G.; Natiu, P.; Gendel, Y. Chlorine-free alkaline seawater electrolysis for hydrogen production. Int. J. Hydrogen Energy 2018, 43, 6504-6514. [CrossRef]

31. Vos, J.G.; Koper, M. Measurement of competition between oxygen evolution and chlorine evolution using rotating ringdisk electrode voltammetry. J. Electroanal. Chem. 2018, 819, 260-268. [CrossRef]

32. Lim, T.; Jung, G.; Joo, S.; Lim, T.; Jung, G.; Kim, J.; Park, S.; Park, J.; Kim, Y.; Kang, S.; et al. Atomically dispersed Pt-N 4 sites as efficient and selective electrocatalysts for the chlorine evolution reaction. Nat. Commun. 2020, 11, 1-11. [CrossRef] [PubMed]

33. Goryachev, A.; Pascuzzi, M.; Francesco, C.; Weber, T.; Over, H.; Hensen, E.; Hofmann, J. Electrochemical stability of $\mathrm{RuO}_{2}(110) / \mathrm{Ru}(0001)$ model electrodes in the oxygen and chlorine evolution reactions. Electrochim. Acta 2020, 336, 135713. [CrossRef]

34. KO, J.; Johnson, J.; Johnson, P.; Xia, Z. Decoupling oxygen and chlorine evolution reactions in seawater using iridium-based electrocatalysts. ChemCatChem 2020, 12, 4526-4532. [CrossRef]

35. Sulay, S.; Pralay, G.; Vijay, R. Facet-dependent chlorine and oxygen evolution selectivity on RuO2: An Ab initio atomistic thermodynamic study. ChemCatChem 2020, 12, 4922-4929.

36. Maiyalagan, T.; Jarvis, K.; Therese, S.; Ferreira, P.; Manthiram, A. Spinel-type lithium cobalt oxide as a bifunctional electrocatalyst for the oxygen evolution and oxygen reduction reactions. Nat. Commun. 2014, 5, 1-8. [CrossRef]

37. Smith, R.; Prevot, M.; Fagan, R.; Zhang, Z.; Sedach, P.; Siu, M.; Trudel, S.; Berlinguette, C. Photochemical route for accessing amorphous metal oxide materials for water oxidation catalysis. Science 2013, 340, 60-63. [CrossRef]

38. Voa, V.; Tran, D.; Le, H.; Kim, N.; Lee, J. Hierarchically porous nickelcobalt phosphide nanoneedle arrays loaded micro-carbon spheres as an advanced electrocatalyst for overall water splitting application. Appl. Catal. B Environ. 2019, 253, 235-245.

39. Sun, H.; Yan, Z.; Liu, F.; Xu, W.; Cheng, F.; Chen, J. Self-supported transition-metalbased electrocatalysts for hydrogen and oxygen evolution. Adv. Mater. 2019, 31, 1806326. 
40. Ling, T.; Zhang, T.; Ge, B.; Han, L.; Zheng, L.; Lin, F.; Xu, Z.; Hu, W.; Du, X.; Davey, K.; et al. Well-dispersed nickel- and zinc-tailored electronic structure of a transition metal oxide for highly active alkaline hydrogen evolution reaction. Adv. Mater. 2019, 31, 1807771. [CrossRef]

41. Ahn, H.; Tilley, T. Electrocatalytic water oxidation at neutral $\mathrm{pH}$ by a nanostructured $\mathrm{Co}\left(\mathrm{PO}_{3}\right)_{2}$ anode. Adv. Funct. Mater. 2013, 23, 227-233. [CrossRef]

42. Dionigi, F.; Reier, T.; Pawolek, Z.; Gliech, M.; Strasser, P. Design Criteria, Operating conditions, and nickel-iron hydroxide catalyst materials for selective seawater electrolysis. ChemSusChem 2016, 9, 962-972. [CrossRef]

43. Cheng, F.; Feng, X.; Chen, X.; Lin, W.; Rong, J.; Yang, W. Synergistic action of Co-Fe layered double hydroxide electrocatalyst and multiple ions of sea salt for efficient seawater oxidation at near-neutral pH. Electrochim. Acta 2017, 251, 336-343. [CrossRef]

44. Liu, W.; Jiang, K.; Hu, Y.; Li, Q.; Deng, Y.; Bao, J.; Lei, Y. Zr-doped CoFe-layered double hydroxides for highly efficient seawater electrolysis. J. Colloid Interface Sci. 2021, 604, 767-775. [CrossRef]

45. Song, F.; Hu, X. Ultrathin cobalt-manganese layered double hydroxide is an efficient oxygen evolution catalyst. J. Am. Chem. Soc. 2014, 136, 16481-16484. [CrossRef]

46. Vos, J.; Wezendonk, T.A.; Jeremiasse, A.; Koper, $\mathrm{M} . \mathrm{MnO}_{\mathrm{x}} / \mathrm{IrO}_{\mathrm{x}}$ as selective oxygen Evolution electrocatalyst in acidic chloride solution. J. Am. Chem. Soc. 2018, 140, 10270-10281. [CrossRef]

47. Okada, T.; Abe, H.; Murakami, A.; Shimizu, T.; Fujii, K.; Wakabayashi, T.; Nakayama, M. A bilayer structure composed of $\mathrm{Mg} \mid \mathrm{Co}-\mathrm{MnO}_{2}$ deposited on a $\mathrm{Co}(\mathrm{OH})_{2}$ film to realize selective oxygen evolution from chloride-containing water. Langmuir 2020, 36, 5227-5235. [CrossRef]

48. Singh, R.; Pandey, J.; Anitha, K. Preparation of electrodeposited thin films of nickel-iron alloys on mild steel for alkaline water electrolysis. Part I: Studies on oxygen evolution. Int. J. Hydrogen Energy 1993, 18, 467-473. [CrossRef]

49. Jayalakshmi, M.; Puspitasari, I.; Jung, K.; Joo, O. Effect of different substrates on the electrochemical behavior of Ni-Mo-Fe-Co-S composite film in alkali solutions. Int. J. Electrochem. Sci. 2008, 3, 787-796.

50. Balram, A.; Zhang, H.; Santhanagopalan, S. Enhanced oxygen evolution reaction electrocatalysis via electrodeposited amorphous $\alpha$-phase nickel-cobalt hydroxide nanodendrite forests. ACS Appl. Mater. Interfaces 2017, 9, 28355-28365. [CrossRef]

51. Huang, X.; Chang, S.; Lee, W.; Ding, J.; Xue, J. Three-dimensional printed cellular stainless steel as a high-activity catalytic electrode for oxygen evolution. J. Mater. Chem. A 2017, 5, 18176-18182. [CrossRef]

52. Cheng, P.; Yuan, C.; Zhou, Q.; Hu, X.; Li, J.; Lin, X.; Wang, X.; Jin, M.; Shui, L.; Gao, X. Core-shell MoS 2 @ CoO electrocatalyst for water splitting in neural and alkaline solutions. J. Phys. Chem. C 2019, 123, 5833-5839. [CrossRef]

53. Gayen, P.; Saha, S.; Ramani, V. Selective seawater splitting using pyrochlore electrocatalyst. ACS Appl. Energy Mater. 2020, 3 , 3978-3983. [CrossRef]

54. Gupta, S.; Forster, M.; Yadav, A.; Cowan, A.; Patel, N.; Patel, M. Highly efficient and selective metal oxy-boride electrocatalysts for oxygen evolution from alkali and saline solutions. ACS Appl. Energy Mater. 2020, 3, 7619-7628. [CrossRef]

55. Zhang, B.; Wang, J.; Wu, B.; Guo, X.; Wang, Y.; Chen, D.; Zhang, Y.; Du, K.; Oguzie, E.; Ma, X. Unmasking chloride attack on the passive film of metals. Nat. Commun. 2018, 9, 1-9. [CrossRef]

56. Liu, X.; Gong, M.; Xiao, D.; Deng, S.; Liang, J.; Zhao, T.; Lu, Y.; Shen, T.; Zhang, J.; Wang, D. Turning waste into treasure: Regulating the oxygen corrosion on Fe foam for efficient electrocatalysis. Small 2020, 16, 2000663. [CrossRef]

57. Sherif, E.; Erasmus, R.; Comins, J. In situ Raman spectroscopy and electrochemical techniques for studying corrosion and corrosion inhibition of iron in sodium chloride solutions. Electrochim. Acta 2010, 55, 3657-3663. [CrossRef]

58. Zhang, X.; Yu, G.; Han, E. Study on the corrosion inhibition mechanism of the gas phase corrosion inhibitor of cyclohexene on thin film of zinc. Chin. J. Corros. Prot. 2003, 3, 175-178.

59. Finke, C.; Omelchenko, S.; Jasper, J.; Lichterman, M.; Read, C.; Lewis, N.; Hoffmann, M. Enhancing the activity of oxygenevolution and chlorine-evolution electrocatalysts by atomic layer deposition of $\mathrm{TiO}_{2}$. Energy Environ. Sci. 2019, 12, 358-365. [CrossRef]

60. Kai, S.; Sohrabnejad-Eskan, I.; Over, H. A universal approach to determine the free energy diagram of an electrocatalytic reaction. ACS Catal. 2018, 8, 1864-1879.

61. Yan, Z.; Song, L.; Tang, M.; Feng, Z. Oxygen Evolution Efficiency and Chlorine Evolution Efficiency for Electrocatalytic Properties of $\mathrm{MnO}_{2}$-based Electrodes in Seawater. J. Wuhan Univ. Technol. Mater. 2019, 34, 69-74. [CrossRef]

62. Dong, G.; Xie, F.; Kou, F.; Chen, T.; Wang, F.; Zhou, Y.; Wu, K.; Du, S.; Fang, M.; Ho, J. NiFe-layered double hydroxide arrays for oxygen evolution reaction in fresh water and seawater. Mater. Today Energy 2021, 22, 100883. [CrossRef]

63. Song, H.; Yoon, H.; Ju, B.; Lee, D.; Kim, D. Electrocatalytic selective oxygen evolution of carbon-coated $\mathrm{Na}_{2} \mathrm{Co}_{1-\mathrm{x}} \mathrm{Fe}_{\mathrm{x}} \mathrm{P}_{2} \mathrm{O}_{7}$ nanoparticles for alkaline seawater electrolysis. ACS Catal. 2019, 10, 702-709. [CrossRef]

64. Wu, X.; Zhou, H.; Wang, S.; Liu, Z.; Pei, S.J.; Yang, W.; Zhao, P.; Qiu, J. Engineering multifunctional collaborative catalytic interface enabling efficient hydrogen evolution in all $\mathrm{pH}$ range and Seawater. Adv. Energy Mater. 2019, 9, 1901333. [CrossRef]

65. Hou, X.; Gao, L.; Cui, Z.; Yin, J. Corrosion and protection of metal in the seawater desalination. IOP Conf. Ser. EES 2018, 108, 022037. [CrossRef]

66. Yu, L.; Zhu, Q.; Song, S.; McElhenny, B.; Wang, D.; Wu, C.; Qin, Z.; Bao, J.; Yu, Y.; Chen, S.; et al. Non-noble Metal-nitride Based Electrocatalysts for High-performance Alkaline Seawater Electrolysis. Nat. Commun. 2019, 10, 5106. [CrossRef]

67. Jadhav, A.; Kumar, A.; Lee, J.; Yang, T.; Na, S.; Lee, J.; Luo, Y.; Liu, X.; Whang, J.; Liu, Y. Stable complete seawater electrolysis by using interfacial chloride ion blocking layer on catalyst surface. J. Mater. Chem. A 2020, 8, 24501-24514. [CrossRef] 
68. Geim, A.; Novoselov, K. The rise of graphene. Nat. Mater. 2007, 6, 183-191. [CrossRef]

69. Wang, Y.; Wilkinson, D.; Zhang, J. Noncarbon support materials for polymer electrolyte membrane fuel cell electrocatalysts. Chem. Rev. 2011, 111, 7625-7651. [CrossRef]

70. Ding, R.; Li, W.; Wang, X.; Gui, T.; Li, B.; Han, P.; Tian, H.; Liu, A.; Wang, X.; Liu, X. A brief review of corrosion protective fifilms and coatings based on graphene and graphene oxide. J. Alloys Compd. 2018, 764, 1039-1055. [CrossRef]

71. Chauhan, D.; Quraishi, M.; Ansari, K.; Saleh, T. Graphene and graphene oxide as new class of materials for corrosion control and protection: Present status and future scenario. Prog. Org. Coat. 2020, 147, 105741. [CrossRef]

72. Wang, M.; Tang, M.; Chen, S.; Ci, H.; Wang, K.; Shi, L.; Lin, L.; Ren, H.; Shan, J.; Gao, P. Graphene-armored aluminum foil with enhanced anticorrosion performance as current collectors for lithium-ion battery. Adv. Mater. 2017, 29, 1703882. [CrossRef]

73. Zhu, Y.; Murali, S.; Cai, W.; Li, X.; Suk, J.; Potts, J.; Ruoff, R. Graphene and graphene oxide: Synthesis, properties, and applications. Adv. Mater. 2010, 22, 3906-3924. [CrossRef]

74. Vikas, B. Impermeability of graphene and its applications. Carbon 2013, 62, 1-10.

75. Wu, Z.; Ren, W.; Gao, L.; Zhao, J.; Chen, Z.; Liu, B.; Tang, D.; Yu, B.; Jiang, C.; Cheng, H. Synthesis of graphene sheets with high electrical conductivity and good thermal stability by hydrogen arc discharge exfoliation. ACS Nano 2009, 3, 411-417. [CrossRef]

76. Kang, D.; Kwon, J.; Cho, H.; Sim, J.; Hwang, H.; Kim, C.; Kim, Y.; Ruoff, R.; Shin, H. Oxidation resistance of iron and copper foils coated with reduced graphene oxide multilayers. ACS Nano 2012, 6, 7763-7769. [CrossRef]

77. Prasai, D.; Tuberquia, J.; Harl, R.; Jennings, G.; Rogers, B.; Bolotin, I. Graphene: Corrosion-inhibiting coating. ACS Nano 2012, 6, 1102-1108. [CrossRef]

78. Kirkland, N.; Schiller, T.; Medhekar, N.; Birbilis, N. Exploring graphene as a corrosion protection barrier. Corros. Sci. 2012, 56, 1-4. [CrossRef]

79. Chen, S.; Brown, L.; Levendorf, M.; Cai, W.; Ju, S.; Edgeworth, J.; Li, X.; Magnuson, C.; Velamakanni, A.; Piner, R.; et al. Oxidation resistance of graphene-coated $\mathrm{Cu}$ and $\mathrm{Cu} / \mathrm{Ni}$ alloy. ACS Nano 2011, 5, 1321-1327. [CrossRef]

80. Huang, Y.; Lo, T.; Chao, C.; Whang, W. Anti-corrosion characteristics of polyimide/h-boron nitride composite films with different polymer configurations. Surf. Coat. Technol. 2014, 260, 113-117. [CrossRef]

81. Lv, Q.; Han, J.; Tan, X.; Wang, W.; Dong, B. Feather-like NiCoP Holey Nanoarrys for Efficient and Stable Seawater Splitting. ACS Appl. Energy Mater. 2019, 2, 3910-3917. [CrossRef]

82. Shang, X.; Dong, B.; Chai, Y.; Liu, C. In-situ electrochemical activation designed hybrid electrocatalysts for water electrolysis. Sci. Bull. 2018, 63, 853-876. [CrossRef]

83. Kou, Z.; Yu, Y.; Liu, X.; Gao, X.; Wang, J. Potential-dependent phase transition and Mo-enriched surface reconstruction of $\gamma$-CoOOH in a heterostructured $\mathrm{Co}-\mathrm{Mo}_{2} \mathrm{C}$ precatalyst enable water uxidation. ACS Catal. 2020, 10, 4411-4419. [CrossRef]

84. Jiang, K.; Liu, W.; Lai, W.; Wang, M.; Li, Q.; Wang, Z.; Yuan, J.; Deng, Y.; Bao, J.; Ji, H. NiFe layered double hydroxide/FeOOH heterostructure nanosheets as an efficient and durable bifunctional electrocatalyst for overall seawater splitting. Inorg. Chem. 2021, 60, 17371-17378. [CrossRef]

85. Wu, H.; Lu, Q.; Zhang, J.; Wang, J.; Han, X.; Zhao, N.; Hu, W.; Li, J.; Chen, Y.; Deng, Y. Thermal shock-activated spontaneous growing of nanosheets for overall water splitting. NanoMicro Lett. 2020, 12, 1-12. [CrossRef]

86. Li, P.; Wang, S.; Samo, I.; Zhang, X.; Sun, X. Common-ion effect triggered highly sustained seawater electrolysis with additional $\mathrm{NaCl}$ production. Research 2020, 2020,1-9. [CrossRef]

87. Dresp, S.; Thanh, T.; Klingenhof, M.; Brueckner, S.; Strasser, P. Efficient direct seawater electrolysers using selective alkaline $\mathrm{NiFe-LDH}$ as OER catalyst in asymmetric electrolyte feeds. Energy Environ. Sci. 2020, 13, 1725-1729. [CrossRef]

88. Grigoriev, S.; Millet, P.; Fateev, V. Evaluation of carbon supported Pt and Pd nanoparticles for the hydrogen evolution reaction in PEM water electrolysers. J. Power Sources 2008, 177, 281-285. [CrossRef]

89. Millet, P.; Ngameni, R.; Grigoriev, S.; Mbemba, N.; Brisset, F.; Ranjbari, A.; Etievant, C. PEM water electrolyzers: From electrocatalysis to stack development. Int. J. Hydrogen Energy 2010, 35, 5043-5052. [CrossRef]

90. Rossi, R.; Hall, D.; Shi, L.; Cross, N.; Gorski, C.; Hickner, M.; Logan, B. Using a vapor-fed anode and saline catholyte to manage ion transport in a proton exchange membrane electrolyzer. Energy Environ. Sci. 2021, 14, 6041-6049. [CrossRef]

91. Liu, Z.; Han, B.; Lu, Z.; Guan, W.; Li, Y.; Song, C.; Chen, L.; Singhal, S. Efficiency and stability of hydrogen production from seawater using solid oxide electrolysis cells. Appl. Energy 2021, 300, 117439. [CrossRef] 